\title{
IMPLIKASI GAYA BELAJAR DALAM DESAIN BLENDED LEARNING
}

\author{
Z. Mawardi Effendi ${ }^{1}$ \\ Hansi Effendi ${ }^{2}$ \\ Hastria Effendi ${ }^{3}$
}

\begin{abstract}
Each student has their own learning style which can be one of the factors that will support their success in learning. In general, learning styles are divided into: visual, auditory, and kinesthetic. Some students categorized as visual, and others categorized as auditory or kinesthetic. Students tend to process information more quickly if the information obtained in accordance with their style. Lecturers should know the student's learning style so they can design an instruction that suits them. This study aimed to uncover the learning styles of students of Padang State University. The study of literature used to reveal the importance of learning styles to be considered in the blended learning process, both in face-to-face learning and online learning. The research found that $57 \%$ of students have a visual learning style, $27 \%$ have auditory learning style, and the rest have a kinesthetic learning style. These results may be better used as guidelines for lecturers to design blended learning.
\end{abstract}

Keywords: learning style, visual, auditory, kinaesthetic, blended learning

\section{INTISARI}

Setiap mahasiswa memiliki gaya belajar mereka sendiri yang dapat menjadi salah satu faktor penunjang keberhasilan mereka dalam belajar. Secara umum gaya belajar terbagi menjadi: visual, auditori, dan kinestetik. Beberapa mahasiswa dikategorikan sebagai visual, dan yang lainnya dikategorikan sebagai auditori atau kinestetik. Ketika belajar mahasiswa cenderung dapat mengolah informasi lebih cepat jika informasi tersebut didapatkan sesuai dengan gaya mereka. Dosen seharusnya mengenal gaya belajar siswa sehingga dapat merancang pembelajaran yang cocok bagi mereka. Penelitian ini berusaha mempelajari gaya belajar mahasiswa Universitas Negeri padang. Studi literatur digunakan untuk menegaskan pentingnya gaya belajar dipertimbangkan dalam proses blended learning, baik pada pembelajaran tatap muka maupun pembelajaran online. Hasil penelitian menunjukkan bahwa $57 \%$ mahasiswa memiliki gaya belajar visual, $27 \%$ memiliki gaya belajar auditory, dan sisanya memiliki gaya belajar kinestetik. Hasil ini mungkin dapat digunakan sebagai pedoman bagi dosen untuk merancang blended learning.

Kata Kunci: gaya belajar, visual, auditori, kinestetik, blended learning

\footnotetext{
${ }^{1}$ Dosen Fakultas Ekonomi Universitas Negeri Padang

${ }^{2}$ Dosen Jurusan Elektro Fakultas Teknik Universitas Negeri Padang

${ }^{3}$ Dosen Fakultas Ilmu Keolahragaan Universitas Negeri Padang
} 


\section{PENDAHULUAN}

Gaya belajar mahasiswa perlu diperhatikan untuk mengakomodasi kebutuhan mahasiswa yang berbeda-beda dalam pembelajaran (Caraivan, 2011: 3; Bersin, 2003: 4). Penggagas pentingnya gaya belajar berpendapat supaya pembelajaran optimal perlu mem-pertimbangkan gaya belajar peserta didik untuk menentukan model pembelajaran yang sesuai untuk mereka (Pashler, et.al, 2009: 105). Hal ini didukung oleh hasil penelitian Abidin, Rezaee, Abdullah, \& Singh (2011) yang menemukan bahwa gaya belajar sangat menentukan pen-capaian akademik.

Montgomery \& Groat (1998) menuliskan setidaknya ada lima alasan kenapa kita harus memahami gaya belajar dan mempertimbangkannya da-lam pembelajaran. (1) Membuat pembelajaran menjadi sebuah "dialog", dalam artian pembelajaran yang dilakukan ha-ruslah interaktif dan kooperatif. (2) Merespon keberagaman siswa, yang seka-rang ini tidak hanya beragam dalam hal suku dan jenis kelamin, tetapi beragam dalam usia, kebangsaan, dan latar be-lakang budaya. Keberagaman ini akan mempengaruhi setingan kelas dan juga gaya belajar. (3) Mengkomunikasikan pesan, jika kita ingin pesan kita sampai secara optimal, maka kita harus merancang materi dalam berbagai bentuk sesuai dengan gaya belajar. (4) Membuat pembelajaran lebih bermakna. Dosen sering mengajar dengan cara yang dianggapnya terbaik. Padahal sebenar-nya pembelajaran dirancang agar mahasiswa mau dan senang belajar. Dengan mempertimbangkan gaya belajar, pembe-lajaran akan lebih bermakna di sisi maha-siswa karena mereka belajar dengan gaya belajar mereka sendiri. (5) Memper- timbangkan keberlanjutan disiplin ilmu. Dengan mempertimbangkan keberaga-man yang ada pada siswa maka kita akan membuka jalan bagi mahasiswa untuk mau terlibat dan menyelami suatu disiplin ilmu sehingga kelestarian disiplin ilmu akan terjaga.

Banyak definisi gaya belajar yang dijumpai di berbagai literatur. Misalnya gaya belajar didefinisikan sebagai cara belajar seseorang; cara belajar yang disukai seseorang; kebiasaan seseorang untuk berpikir dan memperoses infor-masi; dan cara yang disukai seseorang untuk mendapatkan pengetahuan dan keterampilan (Pritchard, 2009: 41). Pritchard sendiri secara sederhana mendefinisikan gaya belajar sebagai cara yang disukai untuk belajar; misalnya lebih menyukai gambar daripada teks; belajar dalam kelompok daripada belajar sendiri; atau belajar secara terstruktur daripada tidak terstruktur (Pritchard, 2009:41-42). Jadi konsep gaya belajar mengacu ke-pada perbedaan individu dalam hal model pembelajaran apa yang paling efektif bagi mereka.

Tujuan penelitian ini yaitu mela-kukan studi literatur tentang gaya belajar dan implikasinya terhadap perancangan blended learning. Selain itu juga akan dilakukan survey awal mengenai gaya belajar mahasiswa di Program Studi Pendidikan Teknik Elektro, Pendidikan Ekonomi, dan IImu Keolahragaan di Universitas Negeri Padang. Dari hasil survey akan dianalisis bagaimana kemungkinan desain blended learning.

\section{PENDEKATAN PEMECAHAN MASALAH}

Penelitian ini merupakan penelitian awal yang dapat dijadikan acuan untuk mengembangkan model blended learning di UNP. Penelitian ini mencakup kajian 
literatur dan Survey di tiga program studi di UNP yakni: Program Studi Teknik Elektro, Pendidikan Ekonomi, dan IImu Keolahragaan. Penelitian ini dilakukan pada semester Genap (Januari-Juni) 2015.

Data yang didapatkan yaitu doku-mentasi mengenai teori tentang gaya belajar dan data hasil survey mengenai gaya belajar mahasiswa. Data diolah menggunakan statistik deskriptif.

\section{HASIL DAN PEMBAHASAN Studi Literatur Mengenai Gaya Belajar}

Gaya belajar dikelompokkan dengan berbagai cara. Honey dan Mumford (dalam Pritchard, 2009:4243) misalnya, mengelompokkan gaya belajar ke dalam empat tipe yakni: (1) Activist yang lebih suka belajar dengan melakukan sesuatu daripada membaca dan mendengar; (2) Reflectors lebih suka mengumpulkan informasi sebanyak mungkin sebelum membuat suatu keputusan sebagai hasil belajar mereka; (3) Theorists suka menerima dan mengintegrasikan semua hasil obser-vasinya ke dalam suatu kerangka yang memungkinkannya melihat hubungan antara suatu observasi dengan observasi lainnya; dan (4) Pragmatists yang suka menemukan dan membuat ide yang baru. Mereka lebih suka mencari implikasi praktis setiap ide atau teori baru sebelum mempertimbangkan berdasarkan nilai mereka sendiri.

\section{Selain itu sebuah riset yang bernama Neuro-Linguistic Programming (NLP)} mengelompokkan gaya belajar berdasarkan bagaimana manusia berko-munikasi dan mempengaruhi belajar. NLP mengelompokkan gaya belajar menjadi tiga yakni: (1) Visual, (2) Auditory, dan (3) Kinesthetic (Pritchard, 2009:44-46). Orang visual lebih suka belajar dengan melihat. Mereka lebih suka bila informasi dipresentasikan secara visual dalam bentuk diagram, grafik, peta, poster, dan displai. Orang auditori lebih suka belajar dengan mendengarkan. Mereka akan mempe-roleh keuntungan bila belajar dalam bentuk diskusi, kuliah, interviu, mende-ngarkan cerita dan rekaman. Sedangkan orang kinestetik lebih suka belajar dengan mengerjakan sesuatu. Mereka lebih suka belajar melalui kegiatan fisik, kerja lapangan, kerja praktek.

Beberapa ahli lain juga mengu-sulkan beberapa klasifikasi gaya belajar lainnya, misalnya Kolb dalam Montgomery (1998: 3-4) mengusulkan bahwa pebelajar dapat diklasifikasikan menjadi: convergent, divergent, assimilator, dan accommodators. Pebe-lajar konvergen memilki kekuatan dalam kemampuan memecahkan masalah secara efisien, membuat keputusan, dan menggunakan ide praktis untuk meme-cahkan masalah; Pebelajar divergen memiliki kemampuan yang baik dalam menyelesaikan tugastugas yang mem-butuhkan kemampuan imajinatif; Pebe-lajar asimilator memiliki kemampuan untuk menalar secara induktif; Sedang-kan pebelajar akomodator sebetulnya kebalikan dari pebelajar asimilasi yakni memiliki kemampuan untuk menalar secara deduktif.

Selain itu Felder \& Silverman (1988: 675-680) mengkategorikan gaya belajar menjadi: intuitive vs sensitive, global vs sequential, visual vs verbal, dan active vs reflective. Peserta didik dengan gaya belajar intuitif menyukai materi pembelajaran abstrak seperti teori dan makna dari teori tersebut, sedangkan peserta didik dengan gaya belajar sensitif suka belajar fakta dan materi yang konkrit. Selanjutnya peserta didik dengan gaya belajar global belajar dengan mengunakan proses berpikir holistik dan belajar dalam lingkup yang luas, sedangkan peserta didik dengan 
gaya belajar sekuensial lebih suka belajar berurutan setahap demi setahap secara linier. Peserta didik dengan gaya belajar visual belajar dari apa yang mereka lihat seperti gambar, diagram, sedangkan peserta didik dengan gaya belajar verbal lebih menyukai belajar melalui presentasi teks baik tertulis maupun lisan. Akhirnya peserta didik dengan gaya belajar aktif suka belajar secara aktif dengan materi pembelajaran dengan mengaplikasikan dan mencobakan materi pembelajaran dalam kehidupan nyata, sedangkan peserta didik dengan gaya belajar reflektif lebih suka memikirkan materi pembe-lajaran dan melakukan refleksi.

Mahasiswa belajar: 10\% dari apa yang mereka baca, $20 \%$ dari apa yang mereka dengar, $30 \%$ dari apa yang mereka lihat, $50 \%$ dari apa yang mereka lihat dan dengar, $70 \%$ dari apa yang mereka katakan, dan 90\% dari apa yang mereka katakan dan lakukan (Muir, 2001: 1-2).

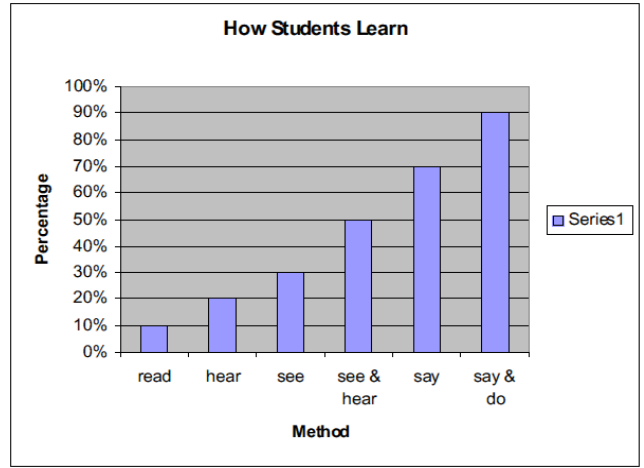

(Sumber: Muir, 2001:2)

Gambar 1. Perbandingan

Bagaimana Mahasiswa Belajar dan

Persentase Serapannya

\begin{tabular}{lr}
\multicolumn{1}{c}{ Berdasarkan apa yang } \\
dipelajari, maka & mahasiswa \\
membutuhkan: & strategi \\
pembelajaran yang bervariasi; jalur \\
pembelajaran yang bervariasi; \\
berbagai aktivitas & yang \\
memungkinkan mereka membaca, \\
menggambarkan,
\end{tabular}

mengatakan, dan melakukan; panduan pembelajaran yang mengarah kepada kemandirian; kemampuan untuk bekerja sendiri dengan metode asesmen yang cocok; dan peralatan dan teknologi yang cocok untuk belajar mandiri dan terbimbing.

Perlu diingat bahwa gaya belajar bukanlah sesuatu yang stabil. Mahasiswa mungkin mengadopsi gaya-gaya yang berbeda tergantung kepada subyek dan lingkungan belajar mereka (Pritchard, 2009). Sebagai contoh, beberapa mahasiswa mungkin memiliki satu atau dua gaya belajar seperti visual, auditori, dan kinestetik, sementara mahaiswa lainnya mungkin memiliki semua gaya belajar ini.

\section{Gaya Belajar dan Pembelajaran Online}

Lu, Gong, Clark, (2007) dalam penelitiannya menghasilkan dua temuan, yaitu: (1) dosen yang menggunakan pem-belajaran online harus secara serius mempertimbangkan keragaman gaya belajar ketika mendesain dan mengem-bangkan modul pembelajaran online, dan (2) harus disediakan dokumen elektronik yang banyak untuk mahasiswa dan memberikan waktu kepada mahasiswa untuk mendapatkan pengetahuan dari membaca.

Esichaikul \& Bechter (2010) menya-takan agar pembelajaran online efektif, maka online learning tersebut harus disesuaikan dengan gaya belajar mahasiswa. Penemuan dalam pene-litiannya mengungkap bahwa mahasiswa dengan gaya belajar yang berbeda cendrung memilih cara belajar yang berbeda juga, seperti lebih memilih tipe diskusi dengan mengirim pesan, alat komunikasi, dan pendekatan penyele-saian masalah.

Berkaitan dengan blended learning, Picciano (2009: 4) pada 
tulisannya "Blending with purpose: the multimodal model" mengembangkan model pembelajaran blended learning dengan konsep multimodal. Dalam tulisannya disarankan model yang baik untuk blended learning yaitu model yang mensinkronkan pembelajaran yang didesain dosen dengan kebutuhan mahasiswa yang beraneka ragam. Hal kritis yang didapat dari pengembangan model ini yaitu bahwa tujuan dan sasaran suatu program akademik mendorong pendekatan peda-gogi dan teknologi yang digunakan.

Berdasarkan penelitian yang ada ini dapat disimpulkan bahwa gaya belajar sangat penting untuk diperhitungkan da-lam desain pembelajaran online. Kaitan-nya yaitu dengan penyediaan dan penya-jian sumber-sumber belajar yang berva-riasi yang sesuai dengan karakteristik matakuliah dan mahasiswa yang akan mempelajarinya. Sebelum melakukan pe-rancangan ada baiknya dilakukan survey awal mengenai kecendrungan gaya belajar mahasiswa, menyesuaikannya de-ngan topik yang akan dipelajari, dan setelah itu merancang pembelajaran yang sesuai.

\section{Survey Gaya Belajar Mahasiswa di UNP}

Survey gaya belajar dilakukan pada tiga program studi di UNP yakni Program Studi Pendidikan Elektro, Pendidikan Ekonomi, dan Program Studi IImu Keolahragaan. Data dari mahasiswa dikumpulkan dengan kuesioner yang diadopsi dari Learning Syle Inventory. Kuesioner berisi dua puluh empat (24) pernyataan yang berhubungan dengan gaya belajar. Mahasiswa memberikan pendapatnya tentang seberapa sering mereka melakukan pernyataan tersebut dalam belajar. Setelah itu kuesioner diolah untuk mengetahui bagaimana kecendrungan gaya belajar mahasiswa. Apakah visual, auditori, atau kinestetik.

Secara keseluruhan diperoleh informasi $57 \%$ mahasiswa memiliki kecendrungan gaya belajar visual, $27 \%$ auditori, dan 16\% memiliki kecendrungan gaya belajar Kinestetik. Secara visual hasil survey ini diperlihatkan melalui Gambar 2. Walaupun ada perbedaan proporsi gaya belajar pada ketiga program studi yang disurvey, tapi pola penyebaran gaya belajar mahasiswa di tiga program studi dimaksud sama yakni sebagian besar mahasiswa memiliki gaya belajar visual, kemudian diiukuti oleh auditori dan kinestetik.

Hasil survey ini sebetulnya sangat menarik. Karena cobalah mengintip kelas yang sedang berlangsung di UNP, kemungkinan besar kita akan mene-mukan orang sedang berbicara. Kalau ditelurusui lebih lanjut siapa yang ber-bicara, maka akan ditemukan sebagian besar pembicaraan didominasi oleh dosen yang sedang mempresentasikan atau mendiskusikan mata kuliahnya.

Kalau dihubungkan dengan hasil survey gaya belajar mahasiswa tentu ini kurang pas. Karena proses pembelajaran yang digunakan hanya lebih mengun-tungkan sebagian kecil mahasiswa yaitu yang memiliki gaya belajar auditori. Walau memang betul juga bahwa klasifikasi gaya belajar mahasiswa tidaklah bersifat "mutually exclusive". 


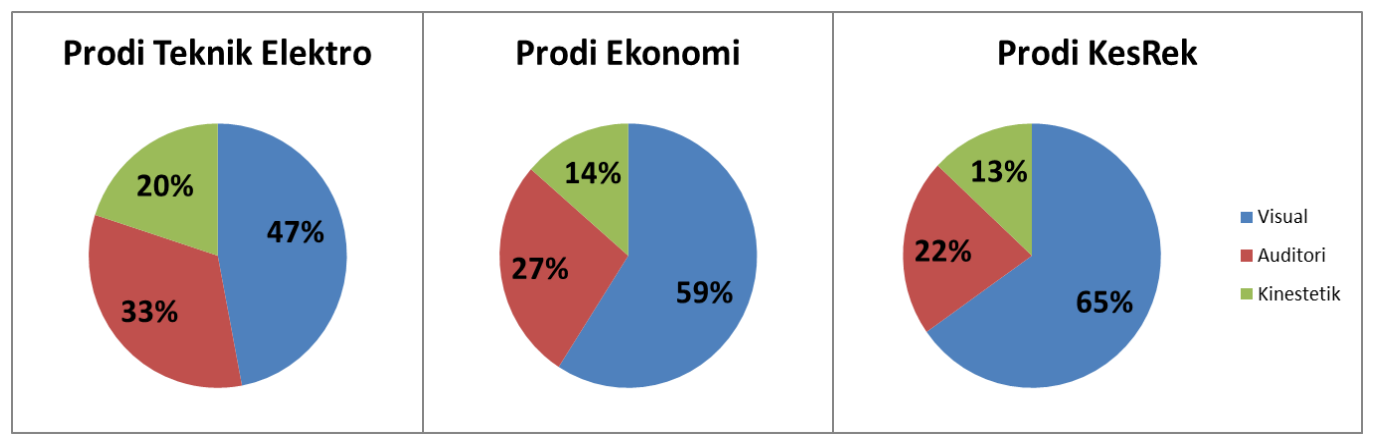

Gambar 2. Gaya Belajar Mahasiswa di Tiga Program Studi UNP

\section{Implikasi Gaya Belajar Mahasiswa dalam Mendisain Blended Learning}

Mengetahui gaya belajar maha-siswa sangat penting dalam rangka mengumpulkan data tentang kecen-derungan mahasiswa belajar, terutama sekali dalam mendesain sistem pembelajaran secara umum. Sehubu-ngan dengan mengakomodasi gaya belajar dalam mendesain sistem pem-belajaran Muir (2001:3) memberikan pendapat yang diringkas pada Tabel 1 .

Selain itu, memahami gaya belajar sendiri akan menciptakan kesadaran bagi mahasiswa.

Tabel 1. Perbedaan Gaya Belajar dan Implikasinya terhadap Desain Pembelajaran

\begin{tabular}{|c|c|c|c|c|c|}
\hline \multicolumn{6}{|c|}{ Pembelajaran } \\
\hline & Pembelajaran & Ujian & Tugas & Referensi & Komunikasi \\
\hline Visual & $\begin{array}{l}\text { Penggunaan } \\
\text { klip video, } \\
\text { diagram, } \\
\text { gambar atau } \\
\text { map }\end{array}$ & $\begin{array}{l}\text { Mengidentifika } \\
\text { si peta, } \\
\text { diagram, } \\
\text { gambar atau } \\
\text { sketsa, } \\
\text { membaca, dan } \\
\text { respon }\end{array}$ & $\begin{array}{l}\text { Peta } \\
\text { konsep } \\
\text { (webbing) } \\
\text { diagram, } \\
\text { konstruksi } \\
\text { presentasi } \\
\text { PowerPoint } \\
\text { membaca }\end{array}$ & $\begin{array}{l}\text { Referensi } \\
\text { map, } \\
\text { diagram, } \\
\text { gambar, } \\
\text { artikel }\end{array}$ & $\begin{array}{l}\text { Menggunaka } \\
\text { n e-white } \\
\text { board, e- } \\
\text { conferen- } \\
\text { cing, chat }\end{array}$ \\
\hline Auditori & $\begin{array}{l}\text { Mendengarkan } \\
\text { kuliah, klip } \\
\text { audio }\end{array}$ & $\begin{array}{l}\text { Identifikasi } \\
\text { suara, atau tes } \\
\text { yang dilakukan } \\
\text { secara verbal }\end{array}$ & $\begin{array}{l}\text { Proyek } \\
\text { dengan } \\
\text { komponen } \\
\text { audio, } \\
\text { interviu, } \\
\text { seminar, } \\
\text { memberika } \\
\text { n laporan } \\
\text { dan pidato, } \\
\text { powerpoint } \\
\text { dengan } \\
\text { komponen } \\
\text { audio }\end{array}$ & $\begin{array}{l}\text { Klip video } \\
\text { atau } \\
\text { audio dari } \\
\text { koleksi } \\
\text { media }\end{array}$ & $\begin{array}{l}\text { Telefon, } \\
\text { audio } \\
\text { conferencing }\end{array}$ \\
\hline
\end{tabular}

Kesadaran ini memberikan kesempatan yang lebih baik bagi mahasiswa untuk mendapatkan penge-tahuan dan juga lebih belajar tidak hanya menciptakan kesadaran bagi mahasiswa tetapi juga dapat digunakan untuk menginformasikan kepada mereka tentang kekuatan dan kelemahan mereka. Dengan disadarinya kekuatan dan kelemahan mereka dalam belajar akan memicu mereka untuk menjadi lebih termotivasi untuk belajar (Coffield et al., 2004 dalam Özbaş, 2012). termotivasi untuk belajar. Gaya 


\begin{tabular}{|l|l|l|l|l|l|}
\hline $\begin{array}{l}\text { Kineste } \\
\text { tik }\end{array}$ & Advanced & Menampilkan & Kuis & Kunjunga & Konferensi \\
& organizer, & tugas, tutorial & asesmen & $\mathrm{n}$ & langsung, \\
& latihan di & multiple & sendiri, & lapangan & kerja \\
& kelas, & choice, & membuat & virtual & kelompok \\
& meminta & laporan/paper, & model, & & \\
& partisipasi & portofolio suatu & presentasi, & & \\
& dalam simulasi & proyek & demo & & \\
& dan demo & & & & \\
& kelas & & & & \\
\hline
\end{tabular}

(Sumber: Muir, 2001: 3)

\section{KESIMPULAN}

Berdasarkan
pendahulu-an yang dilakukan
meliputi: studi literatur mengenai
gaya belajar dan survey pada tiga
program studi di Universitas Negeri
Padang maka dapat disimpulkan
sebagai berikut:

a. Gaya belajar penting dipertimbangkan oleh dosen dalam menentukan model pembelajaran yang akan dirancang untuk mahasiswa.

b. Gaya belajar yang paling populer digunakan untuk mengkategorikan mahasiswa yaitu visual, auditori, dan kinestetik.

c. Hampir lima puluh persen mahasiswa yang mengisi kuesioner gaya belajar di Jurusan Teknik Elektro memilih gaya belajar visual.

d. Dalam merancang blended learning, yang merupakan perpaduan antara tatap muka di kelas dengan e-learning, dosen disarankan memper-timbangkan gaya belajar. Tapi harus diingat bahwa gaya belajar bukanlan sebuah variabel yang mutually exclusive.

\section{DAFTAR PUSTAKA}

[1] Abidin, M.J.Z., Rezaee, A.A., Abdullah, H.N., \& Singh, K.K.B. (2011). Learning styles and overall academic achievement in a specific educational system. International Journal of Humanities and Social Science, 1(10).

[2] Battalio, J. (2009). Success in distance education: do learning styles and multiple formats matter? The Amer. Jrnl. of Distance Education, 23: 71-87.

[3] Bersin, \& Associates. (2003). Blended learning: what works? Diakses pada Tanggal 20 Oktober 2012, dari education-2020.wikispaces. com/file/view/blended bersin.doc.

[4] Boström, L. (2011). Students' learning styles compared with their teachers' learning styles in secondary schools. Institute for Learning Styles Journal, 1, p. 17.

[5] Caraivan, L. (2011). Blended learning: from concept to implementation. Euromentor Journal, II(4).

[6] Diaz, D.P., \& Cartnal, R.B. (1999). Students' learning styles in two classes: online distance learning and equivalent on-campus. College Teaching, 47(4), pp. 130-135.

[7] Esichaikul, V. \& Bechter, C. (2010). Catering for different learning styles in e-learning. Springer.

[8] Felder, R.M. (2002). Learning and teaching styles in engineering education. Engr. Education, 78(7), 674-68. 
[9] Felder, R.M. and Silverman, L.K. (1988). Learning and Teaching Styles in Engineering Educations. Enginee-ring Education, 78(7), 674-681.

[10] Gilakjani, A.P. (2012). Visual, Auditory, Kinaesthetic Learning Styles and Their Impacts on English Language Teaching. Journal of Studies in Education, 2(1).

[11] Gilbert, J. E. \& Swanier, C.A. (2008). Learning Styles: How Do They Fluctuate? Institute for Learning Styles Journal, 1, pp. 29-40.

[12] Graf, S. Viola, S.R. \& Leo, T. (2007). In-Depth Analysis of the Felder-Silverman Learning Style Dimensions. Journal of Research on Technology in Education, 40(1), pp. 79-93

[13] Keefe, J. W. (1987). Learning styles: Theory and practice. Reston, VA: National Association of Secondary School Principals.

[14] Kolb, D. A. (1984). Learning style inventory. Boston: McBerr.

[15] Koob, J.J. \& Funk, J. (2002). Kolb's Learning Style Inventory: Issues of Reliability and Validity. Research on Social Work Practice, 12: 293.

[16] Lu, H., Jia, L., Gong, S.H., \& Clark, B. (2007). The Relationship of Kolb Learning Styles, Online Learning Behaviors and Learning Outcomes. Educational Technology \& Society, 10 (4), 187-196.

[17] Montgomery, S.M., \& Groat, L.N. (1998). Student learning styles and their implications for teaching. The University of Michigan: The Center for Research on Learning and Teaching.

[18] Muir, D.J. (2001). Adapting online education to different learning styles. National
Educational Computing

Conference, "Building on the Future" July 25-27, Chicago, IL.

[19] Özbaş, S. (2012). The Investigation of the Learning Styles of University Students. The Online Journal of New Horizons in Education, 3(1).

[20] Pashler, H., McDaniel, M., Rohrer, D. \& Bjork, R. (2009). Learning styles, concepts, and evidence. Psychological Science in The Public Interest, 9(3). Association for Psychological Science.

[21] Picciano, A. G. (2009). Blending with purpose: the multimodal model. Journal of Asynchronous Networks, 13(1), 7-18.

[22] Pritchard, A. (2009). Ways of learning: Learning theories and learning styles in the classroom, 2nd ed. New York: Routledge Taylor \& Francis Group.

[23] Richmond, A. S., \& Cummings, R. (2005). Implementing Kolb's learning styles into online distance education. International Journal of Technology in Teaching and Learning, 1(1), 45-54.

[24] Rogowsky, B.A., Calhoun, B.M. \& Tallal, P. (2015). Matching learning style to instructional method: effects on comprehension. Journal of Educa-tional Psychology, 107(1), pp. 64-78.

[25] West, W., Rosser, B.R.S., Monani, S. \& Gurak, L. (2006). How Learning Styles Impact Elearning: a case comparative study of undergra-duate students who excelled, passed, or failed an online course in scientific/technical writing. E-Learning, 3(4).

[26] Willems, J. (2011). Using learning styles data to inform e-learning design: A study comparing undergraduates, 
VOL. 8 NO. 1 Maret 2015

\author{
postgraduates and e- \\ educators. Australasian \\ Journal of Educational \\ Technology, 27(6), pp. 863- \\ 880.
}

[27] Zapalska, A. \& Brozik, D. (2006). Learning styles and online education. CampusWide Informat-ion Systems, 23(5), pp. 325-335. 